\title{
PENGARUH VOID PADA PENAMPANG TIANG FONDASI TERHADAP P-Y CURVE
}

\author{
Dave Laurent ${ }^{1}$ dan Alfred Jonathan Susilo \\ ${ }^{1}$ Program Studi Sarjana Teknik Sipil, Universitas Tarumanagara, Jl. Letjen S. Parman No.1 Jakarta \\ Email:dave.laurent@hotmail.com \\ ${ }^{2}$ Program Studi Sarjana Teknik Sipil, Universitas Tarumanagara, Jl. Letjen S. Parman No.1 Jakarta \\ Email: alfredsusilo@gmail.com
}

\begin{abstract}
ABSTRAK
Analisa daya dukung lateral merupakan aspek penting dalam perancangan fondasi untuk mengantisipasi kegagalan fondasi tiang. Salah satu metodenya adalah p-y curve yang merupakan pengembangan dari metode Balok pada Fondasi Winkler. Metode p-y curve memodelkan tanah sebagai pegas non-linier. Metode ini diperkenalkan oleh McClelland dan Focht pada tahun 1956 dalam bentuk kurva hubungan reaksi tanah dengan defleksi akibat beban lateral. Metode p-y curve lebih umum digunakan karena tahap pengerjaannya yang tidak rumit jika dibandingkan dengan metode lainnya dan hasilnya dapat diandalkan. Akan tetapi, metode p-y curve tidak memperhitungkan pengaruh bentuk penampang karena tiang disederhanakan menjadi model tiang satu dimensi dengan pendekatan empiris. Penelitian ini membandingkan pengaruh lubang pada penampang spun pile dan tiang baja tubular terhadap p-y curve menggunakan metode yang diusulkan oleh Georgiadis (2010) dengan p-y curve yang dibentuk dengan program LPILE. Hasil dari penelitian ini menunjukkan bahwa p-y curve untuk tiang dengan penampang solid lebih kaku daripada tiang dengan penampang void.
\end{abstract}

Kata kunci : p-y curve, LPILE, Georgiadis, lateral, Winkler

\section{PENDAHULUAN}

Setiap tahun jumlah penduduk DKI Jakarta terus meningkat. Berdasarkan data dari Badan Pusat Statistik DKI Jakarta (BPS DKI Jakarta), pada tahun 2000 jumlah penduduk DKI Jakarta mencapai 8,4 juta jiwa, tahun 2010 bertambah menjadi 9,6 juta jiwa dan pada tahun 2017 mencapai 10,35 juta jiwa. Dengan luas wilayah 622,3 km2 dan jumlah penduduk yang terus meningkat setiap tahun, lahan pemukiman di Jakarta semakin terbatas. Pada tahun 2000, kepadatan penduduk DKI Jakarta mencapai 12.603 jiwa $/ \mathrm{km}^{2}$, meningkat menjadi $14.506 \mathrm{jiwa} / \mathrm{km}^{2}$ pada tahun 2010 dan pada tahun 2017 menjadi $15.629 \mathrm{jiwa} / \mathrm{km}^{2}$.

Pertumbuhan penduduk yang besar ini memberikan tantangan tersendiri dalam ketersediaan lapangan kerja, ruang terbuka hijau, kebersihan dan kesehatan terutama penyediaan lahan. Salah satu solusi untuk mengatasi kurangnya lahan pemukiman adalah dengan membangun hunian bertingkat seperti apartemen dan rumah susun, sehingga lahan dapat digunakan dengan lebih efisien.

Beban dari gedung bertingkat tinggi terlalu besar untuk dipikul dengan fondasi dangkal seperti fondasi tapak, terlebih lagi dengan luasan fondasi yang terbatas (Craighead: 2009, 7). Karena maraknya pembangunan gedung bertingkat, fondasi dalam menjadi umum digunakan.

Terdapat dua jenis beban yang diperhitungkan ketika merancang fondasi tiang yaitu beban aksial dan beban lateral. Pada beberapa kasus, beban rencana yang lebih menentukan adalah beban lateral daripada beban aksial. Beban lateral dapat bersumber dari tekanan tanah pada dinding penahan, tekanan angin, gaya geser dasar seismik, eksentrisitas dari beban aksial, dan lainnya (Kumar: 2011, 5-39).

Banyak metode telah dikembangkan dari tahun ke tahun untuk menganalisis tiang yang dibebani secara lateral seperti Broms (1965), Thompson (1977), Poulos (1980), Georgiandis dan Butterfield (1982) dan Reese (1986). Metodemetode ini memodelkan tiang sebagai balok lentur. Perbedaan utama analisa tiang yang terbebani secara lateral secara umum terdapat pada pendekatan untuk memodelkan tanah seperti metode p-y curve yang dikembangkan dari pemodelan Winkler, pemodelan tanah sebagai kontinum elastis homogen, dan pemodelan menggunakan metode elemen hingga.

Metode Kontinum Elastis Homogen mengasumsikan tanah di sekitar tiang sebagai kontinum tiga-dimensi. Menurut Salgado et al. (2008), pemodelan tanah sebagai Kontinum tiga-dimensi secara konsep merupakan pemodelan yang lebih akurat.

Metode Kontinum Elastis Homogen mengasumsikan tanah di sekitar tiang sebagai kontinum tiga-dimensi. Menurut Salgado et al. (2008), pemodelan tanah sebagai Kontinum tiga-dimensi secara konsep merupakan pemodelan yang 
lebih akurat. Dibandingkan dengan pemodelan fondasi sebagai balok dua-dimensi karena kondisi tanah yang sebenarnya tiga-dimensi. Penelitian dengan pendekatan ini di rintis oleh Paulos (1971), yang memodelkan tanah sekitar tiang sebagai suatu kontinum dan tiang fondasi sebagai garis yang memberikan tekanan pada kontinum tanah. Paulos menggunakan solusi balok lentur yang diusulkan oleh Mindlin (1936) untuk menghitung defleksi tiang akibat beban horizontal. Namun metode ini kurang umum dibanding dengan metode p-y curve karena langkah pengerjaannya yang rumit.

Metode lain yang dapat digunakan untuk menganalisa fondasi tiang adalah Metode Elemen Hingga. Metode ini bertujuan untuk mempermudah penyelesaian analisis fungsi matematika yang sulit dipecahkan. Logan (2012) mendeskripsikan Metode Elemen Hingga sebagai metode yang mendekati solusi analisis dengan metode numerik dan memecah objek menjadi elemen berhingga yang lebih kecil sehingga solusi persamaan diferensial yang rumit dapat diselesaikan dengan persamaan aljabar simultan. Metode ini memiliki beberapa keunggulan yang tidak dimiliki oleh metode-metode lain. Metode Elemen Hingga dapat mensimulasi interaksi tiang dengan tanah secara tiga-dimensi, baik secara linier maupun non-linier dengan memasukkan karakter dan mekanika bahan dalam bentuk parameter seperti modulus elastisitas dan ratio Poisson atau menambahkan hunbungan non-linier. Pemilihan modulus elastisitas dan ratio Poisson sangat berpengaruh terhadap hasil dari Metode Elemen Hingga, oleh karena itu perlu kecermatan dalam menentukan parameter-parameter tersebut. Diskritisasi model juga mempengaruhi keakuratan hasil metode elemen hingga. Semakin banyak diskritisasi model (h-refinement) dan semakin banyak nodal (p-refinement), makin teliti hasil yang didapat, namun proses analisa akan memakan waktu yang lama dan tidak praktis.

Metode p-y merupakan metode yang umum digunakan karena langkah pengerjaannya tidak terlalu rumit dan hasilnya cukup akurat. Menurut Ashour dan Norris (2000), penyederhanaan model interaksi tiang dan tanah pada p-y curve menjadi satu-dimensi mengabaikan pengaruh bentuk penampang dan interaksi dari komponen tiga-dimensi. Selain itu, metode p-y curve memiliki keterbatasan lain yaitu hanya dapat digunakan untuk tanah yang homogen sepanjang tiang. Sehingga perlu pemilihan p-y curve untuk jenis tanah dan tiang yang tepat karena kurva-kurva yang tersedia dibuat dengan pendekatan empiris.

Ada berbagai macam bentuk penampang fondasi tiang yang digunakan seperti kotak, baja WF, bulat, pipa bulat, bulat berlubang (spun pile) dan lainnya. Namun pada penelitian ini difokuskan pada tiang dengan penampang berlubang seperti spun pile dan tiang baja tubular. Jenis-jenis fondasi ini sering digunakan untuk konstruksi lepas pantai. Menurut GEO Publication No.1/2006 yang dipublikasikan oleh The Government of the Hong Kong Special Administrative Region, Spun pile sering digunakan pada konstruksi lepas pantai karena lebih tahan terhadap korosi dibandingkan dengan tiang beton biasa. Tiang baja tubular makin umum digunakan khususnya untuk konstruksi lepas pantai karena memiliki daya dukung lentur dan tekuk yang tinggi dan memiliki karakter untuk menyerap energi dari beban dinamik. Karena spun pile dan tiang baja tubular umum digunakan, penelitian ini akan lebih berfokus pada jenis tiang spun pile dan tiang baja tubular.

Metode p-y yang terdapat pada literatur menggunakan pendekatan empiris dan tidak terdapat variabel yang dapat mendeskripsikan lubang pada tiang, sehingga penelitian ini mencoba membandingkan metode empiris pada program LPILE dengan metode Georgiadis yang mengikutsertakan pengaruh lubang pada penampang fondasi tiang terhadap p-y curve khususnya perbedaan p-y curve antara tiang berpenampang solid dan tiang void pada penampang.

Masalah pada penelitian ini dibatasi pada tiang dengan kedalaman pemancangan $16 \mathrm{~m}$ yang memiliki bentuk penampang penampang bulat solid dengan diameter $300 \mathrm{~mm}$ hingga $1200 \mathrm{~mm}$, spun pile diameter $300 \mathrm{~mm}$ hingga $1200 \mathrm{~mm}$ sesuai standard WIKA dan tiang baja tubular dengan diameter $1625.6 \mathrm{~mm}$ dan dengan ketebalan $12 \mathrm{~mm}$ hingga $21 \mathrm{~mm}$. Gambar 1.4 menunjukkan jenis penampang tiang yang akan digunakan pada penelitian ini. Tabel 1.1 menunjukkan batasan ukuran tiang yang akan digunakan pada penelitian ini. Data tanah yang digunakan adalah dari Proyek Redevelopment of EX Plaza di Jalan M.H. Thamrin, Jakarta, Indonesia.

\section{METODOLOGI PENELITIAN}

\section{Studi literatur}

Studi literatur merupakan salah satu elemen penting pada penelitian untuk dapat lebih memahami objek penelitian serta yang akan diteliti. Studi literatur yang dilakukan mengacu pada referensi-referensi yang ada seperti buku, jurnal, prosiding, artikel dan situs internet.

Hasil Studi Literatur ini digunakan sebagai landasan teori penelitian ini serta menjadi dasar acuan metode analisis yang digunakan.

\section{Pengumpulan data parameter tanah}

Parameter tanah merupakan elemen terpenting dalam analisa tiang fondasi. Untuk memulai skripsi ini, dimulai dengan melakukan pengumpulan data parameter tanah yang sesuai dengan batasan masalah. Pada penelitian ini digunakan 
data tanah Proyek Redevelopment of EX Plaza di Jalan M.H. Thamrin, Jakarta, Indonesia yang didapat oleh penulis dari PT. China Sonangol Media Investment ketika sedang melakukan kerja praktik di proyek Indonesia 1.

Data tersebut melibatkan dua jenis pengetesan tanah yaitu tes lapangan dan tes laboratorium.

Tes Lapangan mencakup :

o Dutch Cone Penetration Test, dengan kapasitas 2,50 ton pada 12 titik.

o Pengeboran dengan kedalaman 40,00 m sebanyak 1 titik, pengeboran dengan kedalaman 80,00 m sebanyak 4 titik, serta pengeboran dengan kedalaman 150,00 m sebanyak 2 titik.

o Pumping Test yang terdiri dari 1 Pumping Well, dan 6 Observation Well.

Tes Laboratorium mencakup :

o Index Properties

o Tes Atterberg Limit

o Analisis Distribusi Saringan

o Tes Kekuatan

o Tes Konsolidasi

o Swelling Test

Setiap pengetesan baik pengetesan lapangan maupun pengetesan laboratorium mengacu pada American Society for Testing and Material (ASTM) Standard.

\section{Prosedur konstruksi p-y curve}

Data-data parameter tanah yang didapat akan digunakan untuk membuat p-y curve. Penelitian ini akan menggambarkan p-y curve dengan prosedur yang diajukan oleh Georgiadis (2010) berupa kurva hiperbola. Kemudian p-y curve yang diusulkan oleh Reese akan dibuat dengan menggunakan bantuan program LPILE.

\section{Analisis Perbandingan}

Setelah $p$-y curve terbentuk akan dilakukan analisis perbandingan antara hasil $p$-y curve yang dibuat dengan usulan Georgiadis (2010) dan dengan $p$-y curve usulan dari Reese $(1972,1975)$ agar diketahui pengaruh lubang pada penampang terhadap $p-y$ curve.

\section{ANALISIS DATA}

\section{Kondisi dasar tanah}

Pengujian tanah di lapangan mencakup 7 titik bore hole $(\mathrm{BH})$ dan 12 titik sondir. Ditemukan lapisan fill material sedalam 1 meter dari permukaan tanah pada BH-1, BH-2, BH-3, BH-4, BH-5, BH-7 dan lapisan fill material sedalam 4 meter dari permukaan tanah pada BH-6. Kondisi fill material dianggap sama dengan tanah di bawahnya. Rata-rata muka air tanah ditemukan pada kedalaman -3.05 meter dari permukaan dasar tanah. Potongan lapisan tanah dari BH1 sampai dengan BH-7 dapat dilihat pada Gambar 1.

Pada kebanyakan boreholes, dari permukaan hingga sekitar 10.0 meter di bawah permukaan tanah merupakan lapisan tanah silty clay atau clayey silt. Dari kedalaman 10 meter terdapat lapisan tanah silty sand yang sangat padat dengan tebal lapisan 3.0 hingga 5.0 meter. Di bawah lapisan silty sand terdapat lapisan silty clay atau clayey silt hingga kedalaman 20 meter dengan konsistensi very stiff atau hard. 


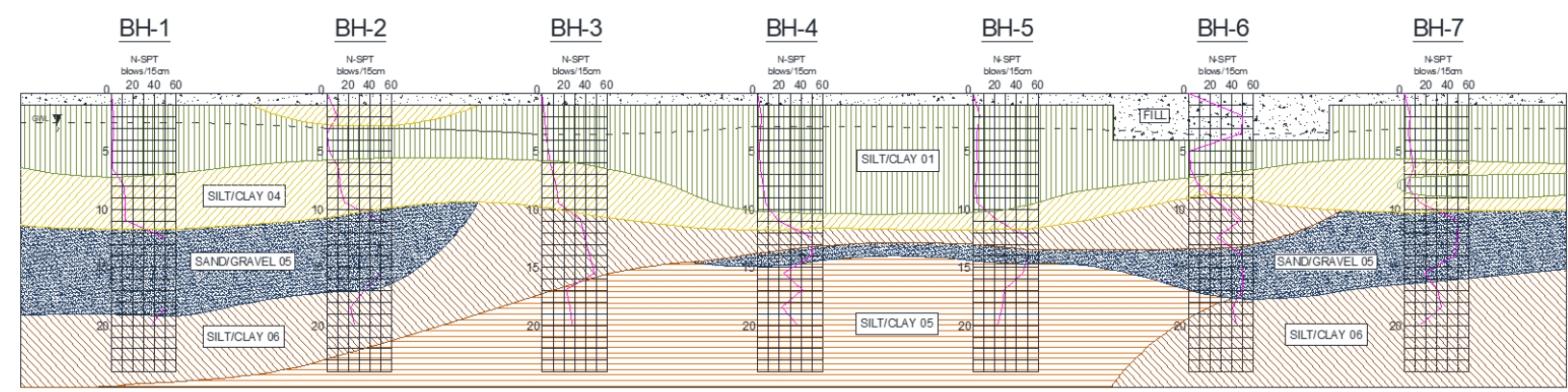

NOT TO SCALE

\begin{tabular}{|c|c|c|c|c|}
\hline \multicolumn{2}{|r|}{ SOIL TYPE } & NSPT & CONSISTENCY/DENSITY & HATCH / ARSIRAN \\
\hline \multirow{6}{*}{ 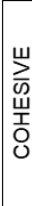 } & SILT/CLAY 01 & $0-2$ & VERY SOFT & \\
\hline & SILT/CLAY 02 & $2-4$ & SOFT & \\
\hline & SILT/CLAY 03 & $4-8$ & MEDIUM & \\
\hline & SILT/CLAY 04 & $8-15$ & STIFF & \\
\hline & SILT/CLAY 05 & $15-30$ & VERY STIFF & \\
\hline & SILT/CLAY 06 & $>30$ & HARD & \\
\hline
\end{tabular}

\begin{tabular}{|c|c|c|c|c|}
\hline \multicolumn{2}{|r|}{ SOIL TYPE } & NSPT & CONSISTENCY/DENSITY & HATCH / ARSIRAN \\
\hline \multirow{5}{*}{ 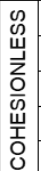 } & SAND/GRAVEL 01 & $0-4$ & VERY LOOSE & \\
\hline & SAND/GRAVEL 02 & $4-10$ & LOOSE & \\
\hline & \begin{tabular}{|l|} 
SAND/GRAVEL 03 \\
\end{tabular} & $10-30$ & MEDIUM DENSE & \\
\hline & SAND/GRAVEL 04 & $30-50$ & DENSE & \\
\hline & SAND/GRAVEL 05 & $>50$ & VERY DENSE & \\
\hline
\end{tabular}

Gambar 1. Stratifikasi dan potongan tanah dengan nilai NSPT terhadap kedalaman

\section{Hyperbolic p-y curve Georgiadis (2010)}

Pada tahun 2010, Georgiadis mengusulkan pendekatan konstruksi p-y curve yang dibandingkan dengan pendekatan Finite Element. Georgiadis memodifikasi persamaan yang sudah sering diadopsi untuk menginterpretasikan hasil tes tiang (Georgiadis et al. 1991; Rajashree dan Sitharam 2001; Kim et al. 2004; Liang et al. 2009). Kurva ini memiliki kemiringan awal Ki dan dideskripsikan dengan persamaan hyperbolic pada Persamaan 1.

$$
p=\frac{y}{\left(\frac{1}{k_{i}}\right)+\left(\frac{y}{p_{u}}\right)}
$$

Penentuan nilai $\mathrm{P}_{\mathrm{u}}$ berdasarkan kedalaman titik yang ditinjau penting dalam konstruksi $p$-y curve. Berdasarkan hasil penelitian Georgiadis (2010), $\mathrm{P}_{\mathrm{u}}$ dapat dihitung dengan persamaan 2.

$$
p_{u}=N_{p} \cdot c_{u} \cdot D
$$

Dimana $\mathrm{N}_{\mathrm{p}}$ merupakan faktor kapasitas daya dukung yang dapat dihitung dengan persamaan 3.

$$
N_{p}=N_{p u}-\left(N_{p u}-N_{p o} \cos \theta\right) e^{-\lambda\left(\frac{z}{D}\right) /(1+\tan \theta)}
$$

Dimana $\mathrm{N}_{\mathrm{pu}}$ adalah faktor kapasitas daya dukung lateral ultimate yang dapat dihitung dengan persamaan $4, \mathrm{~N}_{\mathrm{po}}$ merupakan faktor kapasitas daya dukung pada permukaan untuk tanah horizontal, $\lambda$ merupakan faktor tanpa dimensi, $\mathrm{z}$ merupakan titik kedalaman yang ditinjau dan D merupakan diameter tiang. $\mathrm{N}_{\mathrm{po}}$ dan $\lambda$ diturunkan dari hasil analisa metode elemen hingga yang dilakukan Georgiadis (2010) dan bergantung pada faktor adhesi tiang-tanah $(\alpha)$.

$$
N_{p u}=\pi+2 \Delta+2 \cos \Delta+4\left(\cos \frac{\Delta}{2}+\sin \frac{\Delta}{2}\right)
$$

Dimana $\Delta=\sin ^{-1} \alpha$.

$$
N_{p o}=2+1.5 \alpha
$$

Dan nilai $\lambda$ dapat dihitung dengan persamaan 6.

$$
\lambda=0.55-0.15 \alpha
$$

Besar faktor adhesi tiang-tanah $(\alpha)$ dapat ditentukan dari parameter $\mathrm{c}_{\mathrm{u}}$ dan $\mathrm{z} / \mathrm{D}$ dimana $\mathrm{z}$ adalah kedalaman tiang yang ditinjau dan D adalah diameter tiang dengan grafik yang ditunjukkan pada Gambar 2.

Pada tahun 1961 Vesic mengajukan hubungan korelasi reaksi subgrade $\mathrm{k}_{\mathrm{s}}$ untuk balok pada elastic half-space menjadi properti elastis balok dan tanah. Rajashree dan Sitharam (2001) mengusulkan bahwa kekakuan awal $\mathrm{k}_{\mathrm{i}}$ dari $p-y$ curve adalah dua kali dari nilai $\mathrm{k}_{\mathrm{s}}$ yang ditentukan berdasarkan korelasi usulan Vesic seperti yang ditunjukkan pada persamaan 7.

$$
k_{i}=\frac{1.3 E_{i}}{1-\mu^{2}}\left(\frac{E_{i} D^{4}}{E_{p} I_{p}}\right)^{\frac{1}{12}}
$$

Dimana $\mathrm{E}_{\mathrm{i}}$ adalah modulus elastisitas awal, $\mu$ adalah ratio poisson tanah, $\mathrm{E}_{\mathrm{p}}$ adalah modulus elastisitas tiang, $\mathrm{I}_{\mathrm{p}}$ adalah momen inersia penampang tiang dan $\mathrm{D}$ adalah Diameter tiang. 


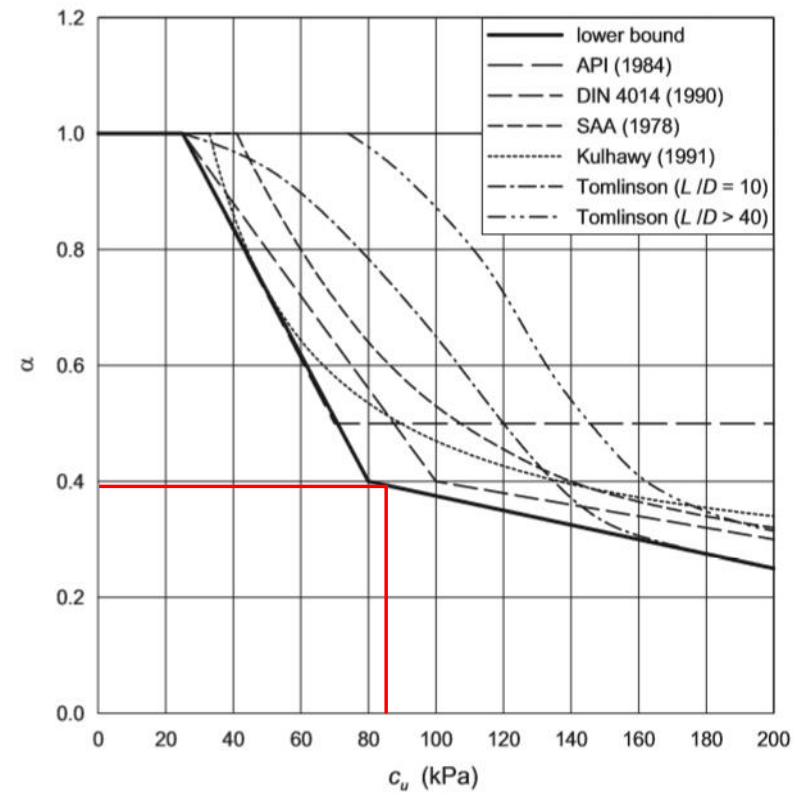

Gambar 2. Grafik hubungan antara $\alpha$ dengan cu $(\mathrm{kPa})$

(Sumber: Georgiadis, 2010)

\section{Analisis LPILE}

Berikut adalah contoh konstruksi $p-y$ curve dengan program LPILE. Pertama-tama input data propertis tanah pada program LPILE seperti yang ditunjukkan pada Gambar 3. Lapisan tanah dihitung dengan metode yang diusulkan oleh Reese dan Welch (1972) untuk tanah diatas muka air tanah dan Reese et al. (1975) untuk tanah di bawah muka air tanah. kedalaman $p-y$ curve ditinjau pada permukaan tanah sama seperti pada analisis $p-y$ curve dengan metode Georgiadis (2010).

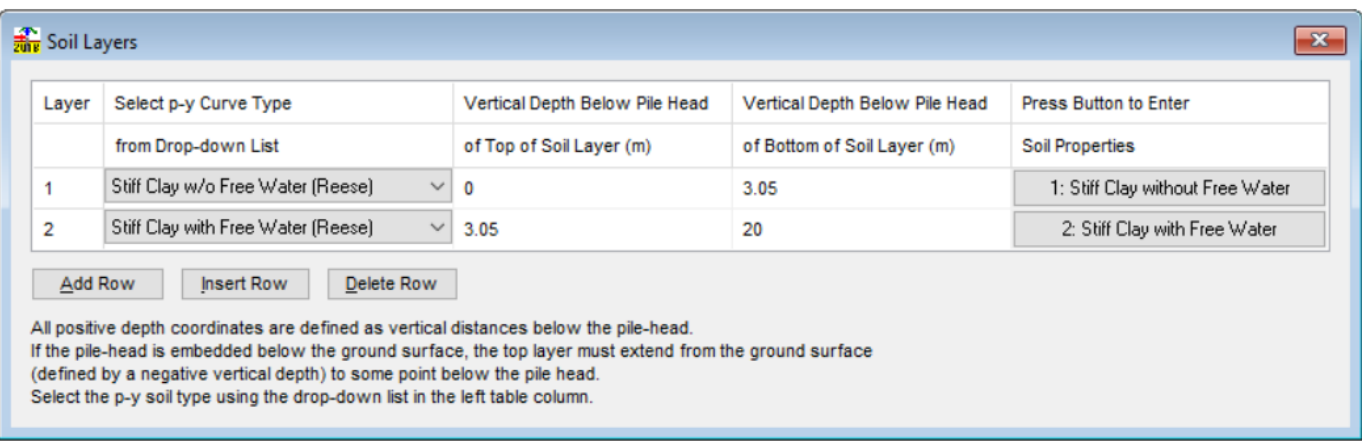

Gambar 3. Pengaturan propertis tanah program LPILE

Setelah melakukan input propertis tanah, input propertis tiang pada program LPILE. Panjang tiang adalah $16 \mathrm{~m}$ dan diameter sesuai dengan batasan masalah. Gambar 4. menunjukkan contoh tampilan input propertis penampang pada program LPILE.

Setelah input selesai, dilakukan analisis dengan menekan tombol "Run Analysis" sehingga hasil analisis akan ditampilkan secara langsung seperti pada Gambar 5. Hasil analisis program LPILE juga dapat di-export dalam format Microsoft Excel dengan memilih "Export Grapgh to Excel" pada menu Graphics. 


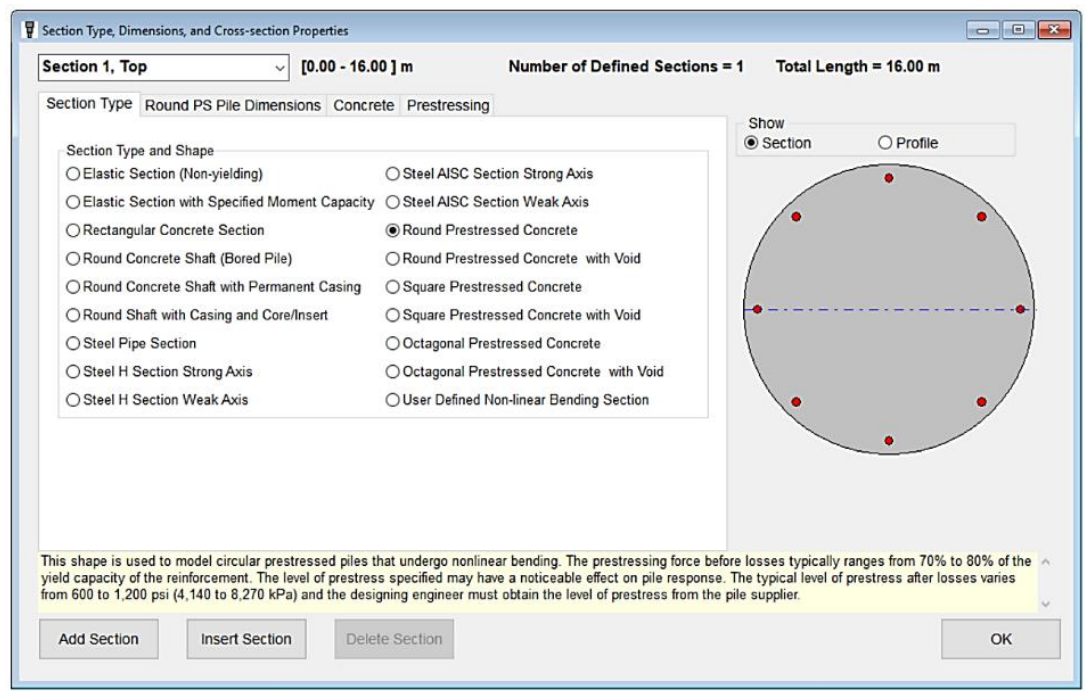

Gambar 4. Tampilan input propertis tiang pada program LPILE

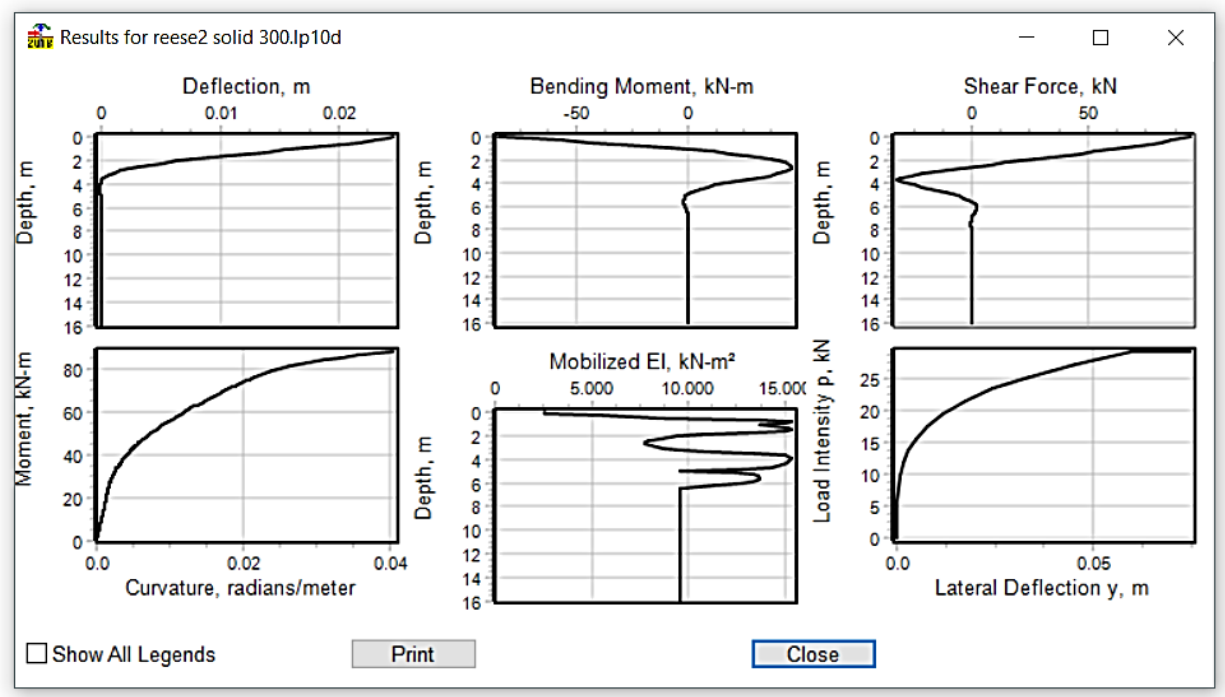

Gambar 5. Tampilan hasil analisis program LPILE

\section{HASIL DAN PEMBAHASAN}

Hasil perhitungan $p$ - $y$ curve tiang beton solid dan spun pile dengan metode Georgiadis (2010) kemudian diplot pada grafik yang ditunjukkan pada Gambar 6. Hasil perhitungan p-y curve tiang baja solid dan tiang baja tubular dengan metode Georgiadis (2010) diplot pada grafik yang ditunjukkan pada Gambar 7. Hasil perhitungan p-y curve tiang beton solid dan spun pile dengan program LPILE diplot pada grafik yang ditunjukkan pada Gambar 8. Hasil perhitungan p-y curve tiang baja solid dan tiang baja tubular dengan program LPILE diplot pada grafik yang ditunjukkan pada Gambar 9.

Dari hasil perhitungan $p-y$ curve dapat terlihat perbedaan antara $p-y$ curve tiang solid dan void dengan metode Georgiadis (2010) yang dipengaruhi oleh momen inersia penampang. 


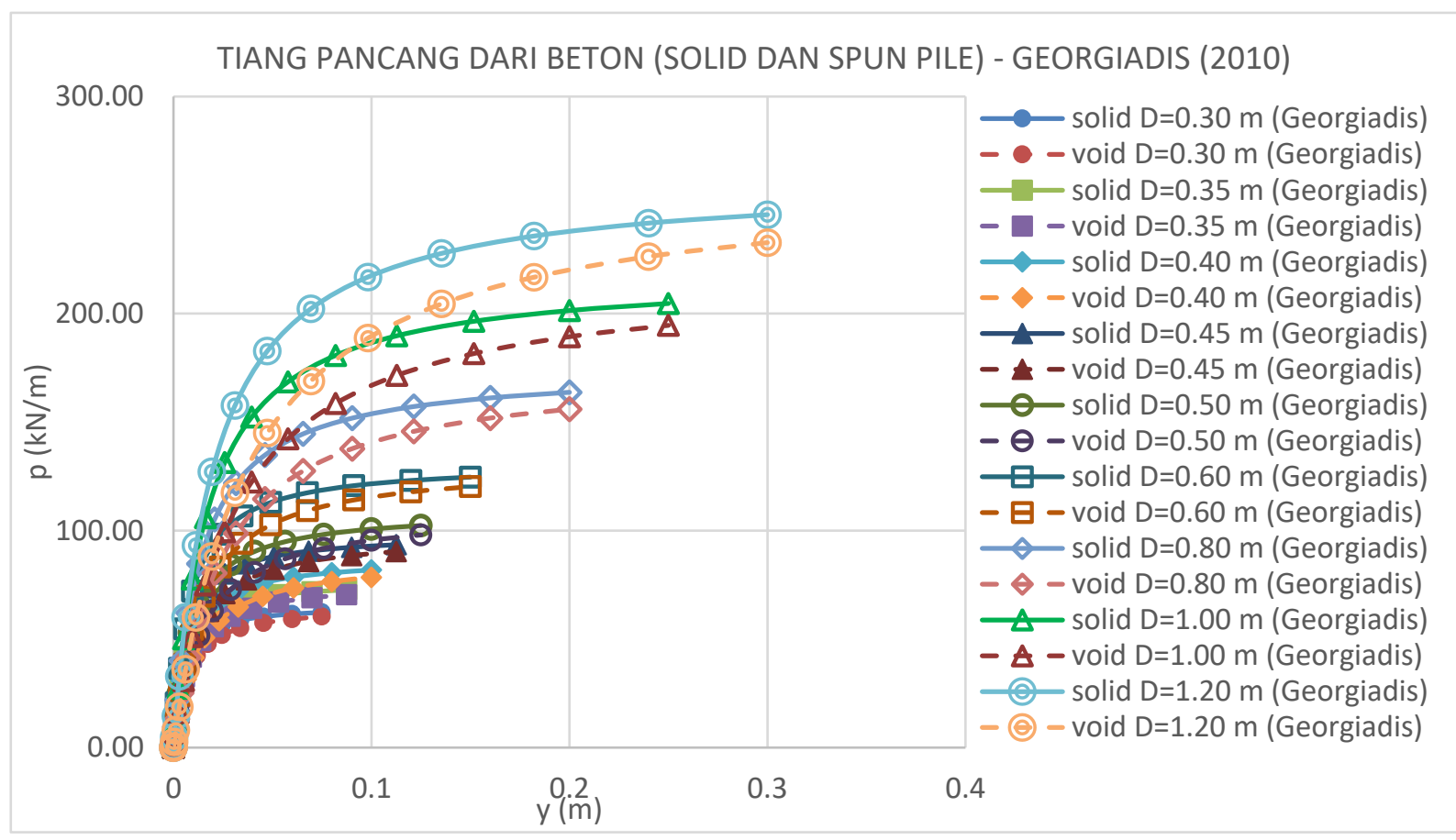

Gambar 6. p-y curve tiang beton solid dan spun pile metode Georgiadis (2010)

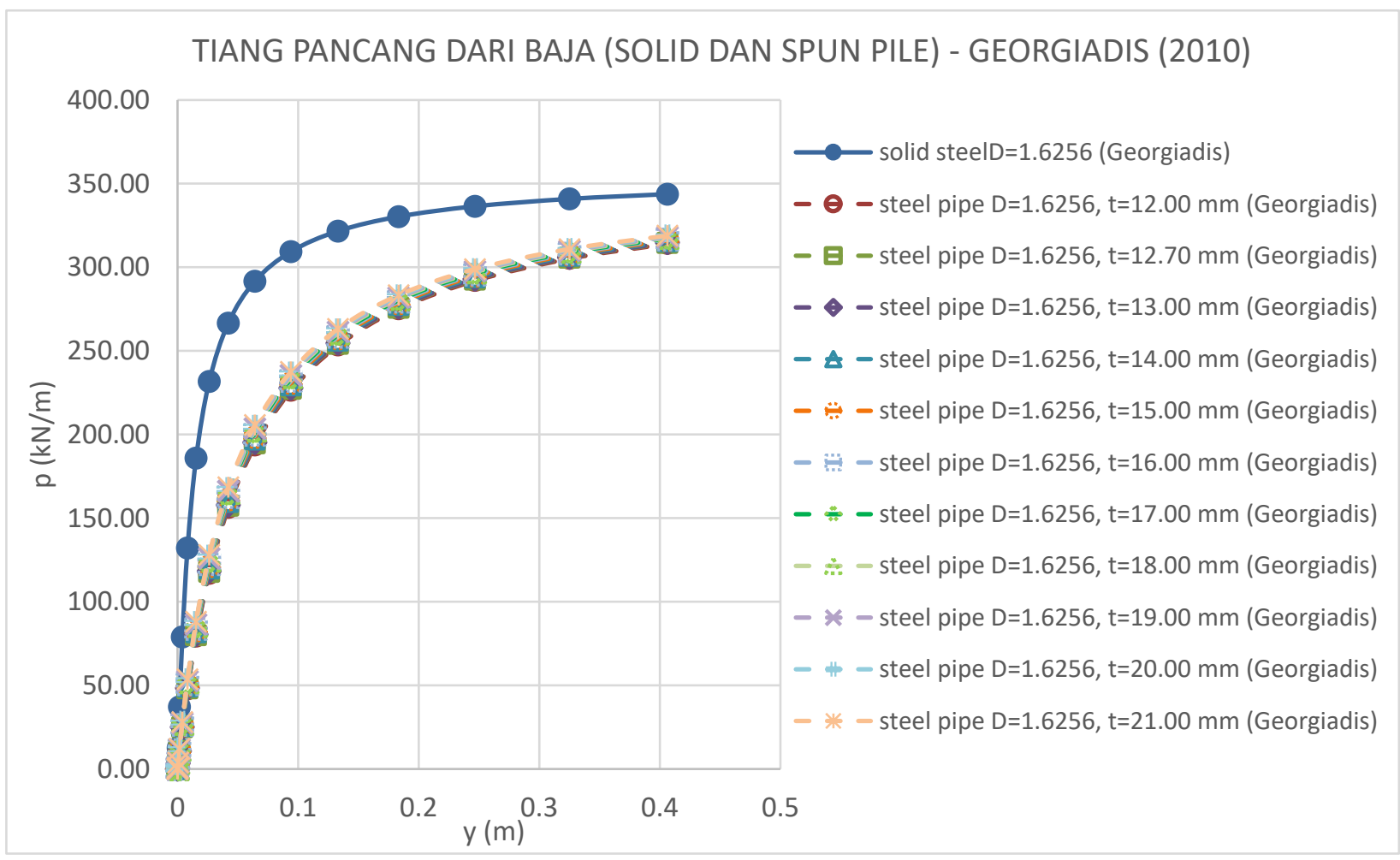

Gambar 7. p-y curve tiang baja solid dan tiang baja tubular metode Georgiadis (2010) 


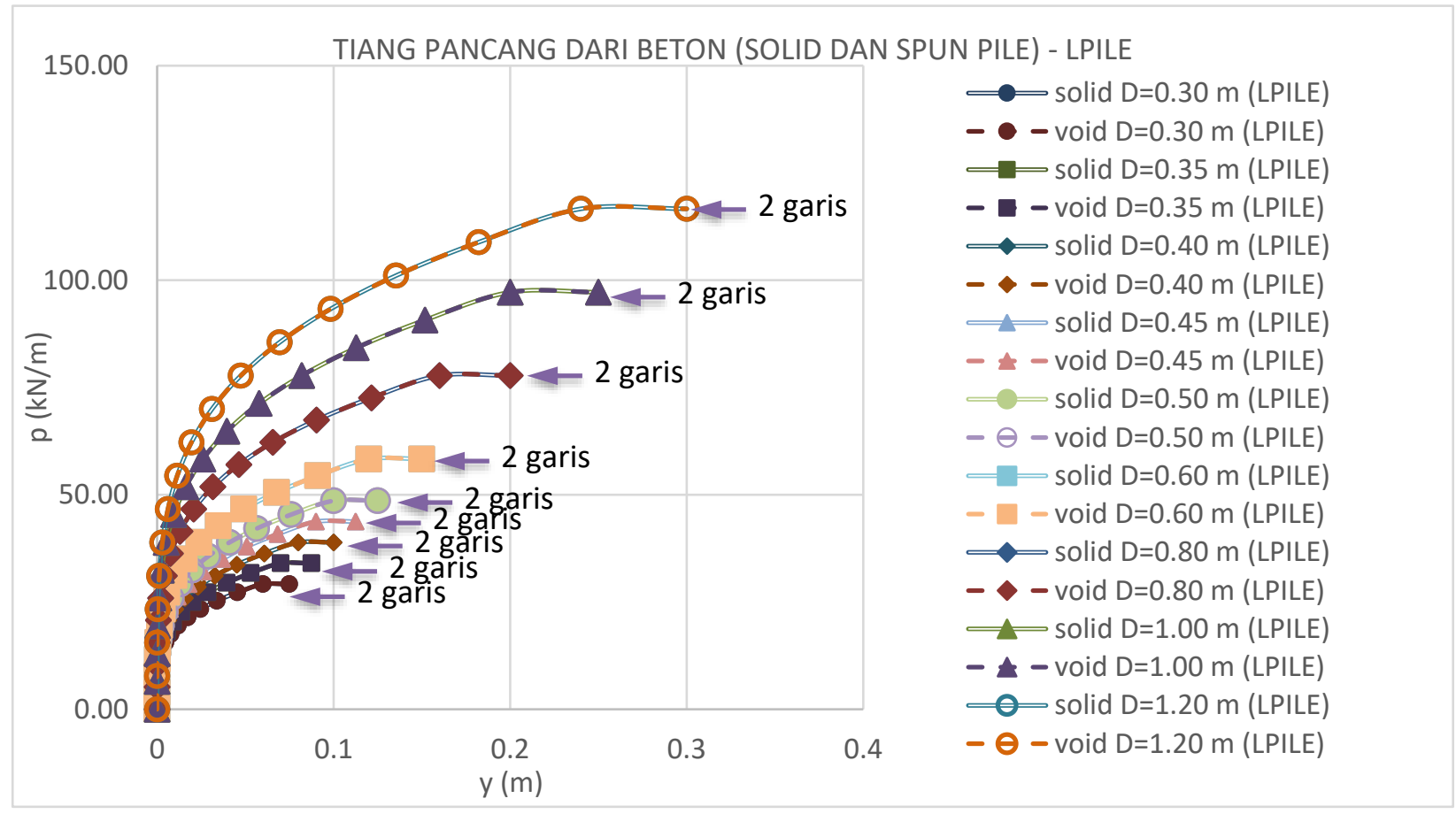

Gambar 8. p-y curve tiang beton solid dan spun pile program LPILE

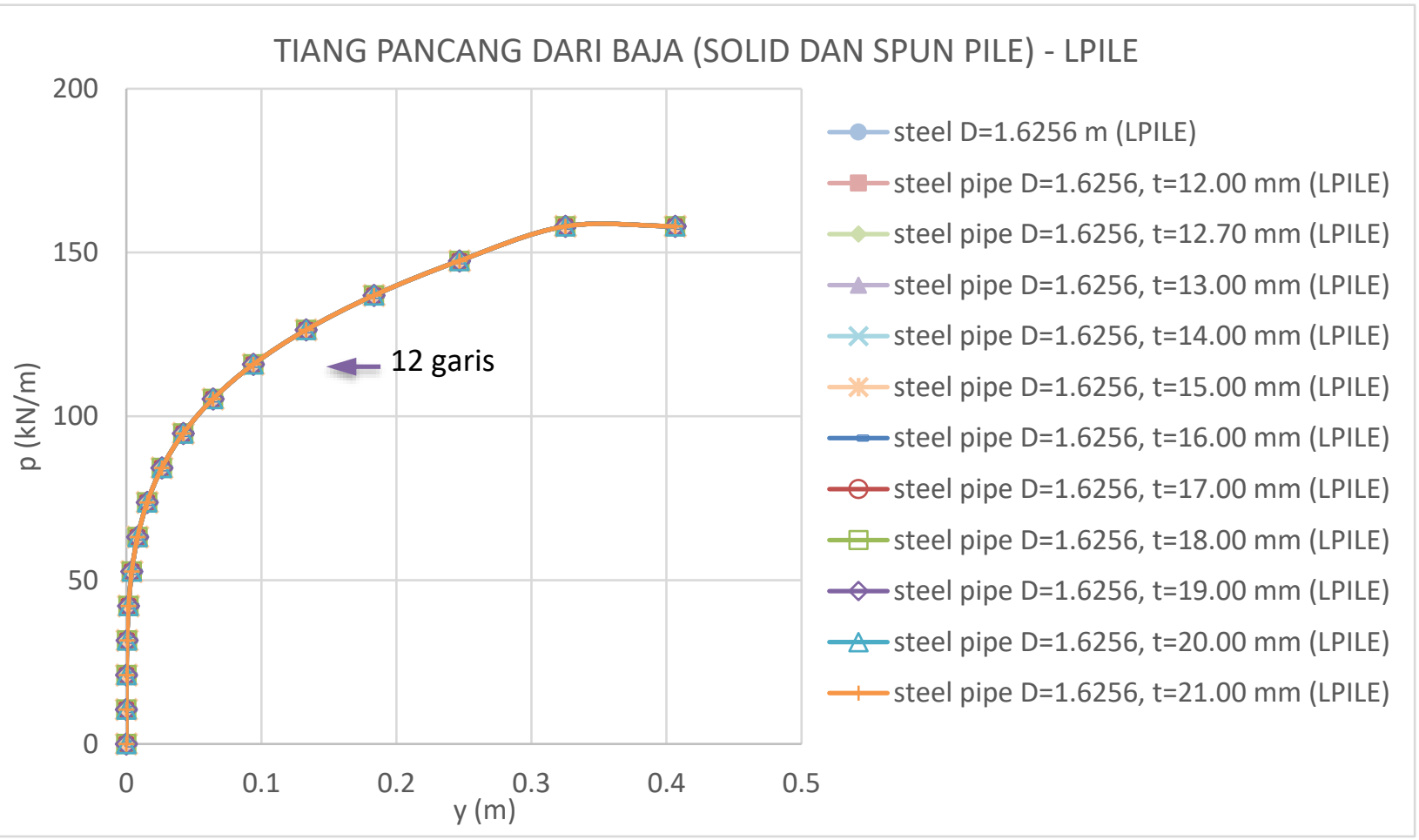

Gambar 9. $p$-y curve tiang baja solid dan tiang baja tubular program LPILE 


\section{KESIMPULAN DAN SARAN}

\section{Kesimpulan}

Dari hasil penelitian yang diperoleh terdapat perbedaan hasil $p$-y curve antara tiang berpenampang penuh (solid) dan tiang void yang dikonstruksi dengan metode yang diusulkan oleh Georgiadis (2010). Ini menunjukkan bahwa metode konstruksi p-y curve yang diusulkan oleh Georgiadis (2010) memperhitungkan pengaruh momen inersia penampang.

Gambar 6 dan Gambar 7 yang di plot dari hasil perhitungan dengan metode yang diusulkan Georgiadis (2010) menunjukkan bahwa bahwa $p$-y curve untuk tiang berpenampang penuh (solid) lebih kaku daripada $p$-y curve untuk tiang berpenampang berlubang (void).

Perbedaan nilai $p$-y curve antara tiang solid dan void untuk tiang beton dengan diameter $0.30 \mathrm{~m}$ sebesar $38.89 \%$ dan terus meningkat perbedaannya pada tiang dengan diameter yang lebih besar. Perbedaan nilai $p-y$ curve antara tiang solid dan void untuk tiang beton dengan diameter 1.20 m mencapai $46.18 \%$. Ini menunjukkan bahwa dengan ratio diameter solid dan void yang sama, makin besar diameter tiang makin besar juga pengaruh lubang (void) pada penampang tiang terhadap $p-y$ curve.

Perbedaan nilai p-y curve antara tiang solid dan void untuk tiang baja berdiameter $1.6256 \mathrm{~m}$ yang dibandingkan dengan tiang baja tubular dengan ketebalan $21.00 \mathrm{~mm}$ sebesar $69.91 \%$ dan terus meningkat perbedaannya jika dibandingkan dengan tiang baja tubular dengan ketebalan yang lebih tipis. Perbedaan nilai p-y curve antara tiang solid dan void untuk tiang baja berdiameter $1.6256 \mathrm{~m}$ yang dibandingkan dengan tiang baja tubular dengan ketebalan 12.00 mm mencapai $73.85 \%$. Ini menunjukkan bahwa makin tipis pipa baja atau dengan kata lain makin besar void pada penampang tiang, makin besar juga pengaruh lubang (void) pada penampang tiang terhadap p-y curve.

Gambar 6 dan Gambar 7 yang diplot dengan bantuan analisis program LPILE menunjukkan perbedaan dengan Gambar 8 dan Gambar 9 yang dihitung dengan metode Georgiadis (2010), perbedaan ini mungkin terjadi karena beda asumsi pemodelan tiang dan tanah antara metode usulan Georgiadis (2010) dan program LPILE.

\section{Saran}

Proyek pembangunan di Indonesia saat ini sedang mengarah ke pembangunan lepas pantai (offshore) yang ditunjukkan dengan adanya proyek-proyek lepas pantai seperti proyek Pelabuhan Patimban di Subang, Pelabuhan atas laut New Priok Container Terminal (NPCT) di Jakarta, proyek reklamasi 17 pulau di Jakarta, serta proyek-proyek lepas pantai lainnya. Jenis tiang yang sering digunakan pada proyek-proyek lepas pantai adalah tiang baja tubular atau spun pile.

Dari hasil penelitian yang didapat pengaruh lubang (void) pada penampang tiang terhadap p-y curve cukup besar khususnya pada tiang-tiang dengan diameter besar. Sehingga disarankan agar para perencana memperhatikan pengaruh lubang (void) pada penampang tiang saat melakukan analisis p-y curve dengan program LPILE.

Penulis menyadari ada banyak kekurangan dalam penelitian ini sehingga perlu dilakukan penelitian lebih lanjut untuk mengkonfirmasi hasil penelitian ini dengan membuat pemodelan tiang-tanah yang lebih akurat dan melakukan pengetesan lapangan.

Topik skripsi ini dapat dikembangkan lagi karena terdapat hubungan antara lendutan dan reaksi tanah dengan kapasitan momen tiang. Lendutan berhubungan dengan kapasitas momen tiang karena momen merupakan turunan kedua dari lendutan yang dikalikan dengan kekakuan tiang dan reaksi tanah juga berhubungan dengan momen tiang karena momen merupakan integrasi kedua dari reaksi tanah, sehingga dapat dilakukan penelitian lebih lanjut mengenai pengaruh lubang pada penampang tiang terhadap kapasitas momen.

Selain spun pile dan tiang baja tubular, terdapat jenis-jenis tiang lainnya yang berlubang sehingga perlu penelitian lebih lanjut mengenai pengaruh lubang pada penampang tiang terhadap p-y curve untuk jenis-jenis tiang lainnya.

\section{DAFTAR PUSTAKA}

Ashour, Mohamed dan G. Norris. "Modelling Lateral Soil-Pile Response Based on Soil-Pile Interaction.” Journal of Geotechnical and Geoenvironmental Engineering (2000): 426.

Bidang Statistik Sosial BPS Provinsi DKI Jakarta. "Statistik Kesejahteraan Rakyat Provinsi DKI Jakarta." 2017. https://jakarta.bps.go.id/. web. 19 Januari 2018.

Craighead, Geoff. High-Rise Security and Fire Life Safety. Oxford: Elsevier, 2009.

Georgiadis, Michael dan Konstantinos Georgiadis. "Undrained Lateral Pile Response in Sloping Ground." Journal of Geotechnical and Geoenvironmental Engineering ASCE (2010).

Isenhower, William M. dan Shin Tower Wang. User's Manual for LPILE 2013. Ensoft, Inc., 2014. 
Juirnarongrit, Teerawut dan Scott A. Ashford. Effect of Pile Diameter on the Modulus of Subgrade Reaction. Research Project. San Diego: University of California, 2001.

Kumar, Sanjeev. "Design of Pile Foundations.” Das, Braja M. Geotechnical Engineering Handbook. Florida: J. Ross Publishing, 2011.

Logan, Daryl L. A First Course in Finite Element Method. Platteville: Global Engineering: Christopher M. Shortt, 2012.

Reese, Lymon C., William R. Cox dan Francis D. Koop. “Analysis of Laterally Loaded Piles in Sand.” Proceeding to 6th Annual Offshore Technology Conference. 1974.

-. "Field Testing and Analysis of Latteraly Loaded Piles in Stiff Clay." Proceeding to 7th Annual Offshore Technology Conference. 1975.

Salgado, Rodrigo, Dipanjan Basu dan Monica Prezzi. Analysis of Laterally Loaded Piles in Multilayered Soil Deposits. Final Report. West Lafayette: Purdue University, 2008.

The Government of the Hong Kong Special Administrative Region. Foundation Design and Construction. Kowloon: Geotechnical Engineering Office, 2006.

Winkler, Dr. E. Die Lehre von der Elasticitaet und Festigkeit. Prag: Dominicus, 1867. 